\title{
Ключевой вектор стратегии Merck в России - трансфер технологий в партнерстве с ведущими российскими компаниями
}

Рассказывает президент и генеральный директор Merck в России и странах СНГ Юрген Кёниг (Juergen Koenig)

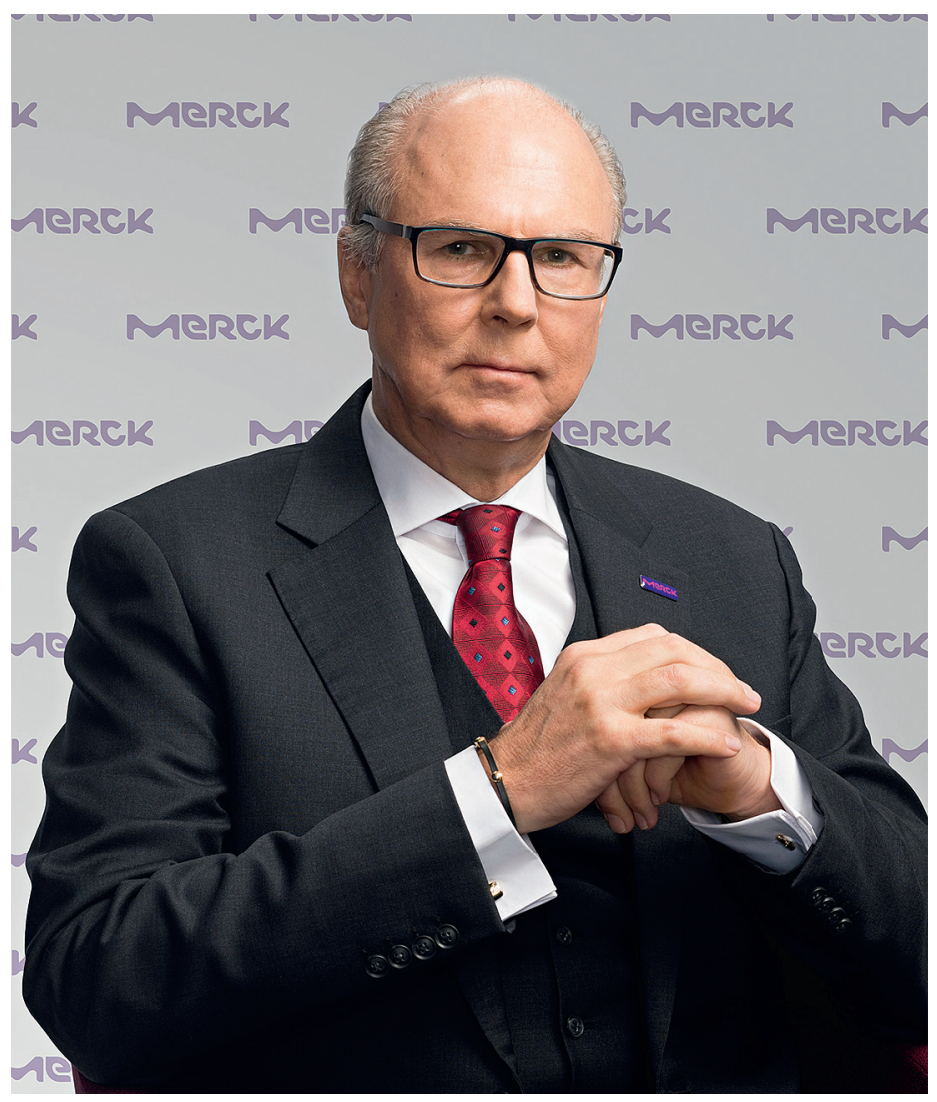

Merck является ведущей научно-технологической компанией в области здравоохранения, лайф сайнс" и высокотехнологичных материалов. Для компании 2019 год - юбилейный: 350 лет со дня основания и 120 лет работы в России. 2 апреля состоялся «Научный диалог Merck» - событие, посвященное укреплению научного обмена между Россией и Германией. На мероприятии выступили известные научные деятели, представители бизнеса и государственной власти. С приветственным словом к участникам и гостям обратился Президент и генеральный директор Merck в России и странах СНГ, Юрген Кёниг. Во время перерыва господин Кёниг любезно согласился рассказать корреспонденту журнала о новых направлениях производства и маркетинга компании.

"Лайф сайнс" - направление работы и название подразделения компании Merck, которое занимается технологиями, оборудованием и материалами для научно-исследовательской и производственной деятельности в области биотехнологий и фармакологии. 
Добрый день, господин Кёниг! Три года назад мы беседовали о ребрендинге и важных нововведениях, которые происходили на тот момент в Merck". Какие наиболее значительные перемены произошли в компании за это время?

В этом году Merck отмечает 350-летний юбилей со дня основания компании и 120-летнюю годовщину начала работы в России. Компания была основана в 1668 году, с тех пор Merck прошел путь от небольшого семейного бизнеса до концерна, производящего материалы для фармацевтической, химической и биологической промышленности с более чем 52 тысячами сотрудников в 66 странах мира.

За последние 10 лет мы стали одной из ведущих научнотехнологических компаний в области здравоохранения, лайф сайнс и высокотехнологичных материалов. Эти стратегические направления компания реализует во всем мире, в том числе и в России. Например, несколько лет назад мы приступили в России к локализации производства линейки сахароснижающих препаратов, и сейчас это производство работает по полному циклу. Еще один пример - открытие в 2017 году в Москве демо-лаборатории Merck по направлению лайф сайнс, на базе которой клиенты совместно с нашими специалистами работают над научно-исследовательскими проектами. За последние пять лет количество наших сотрудников в России выросло в четыре раза и составляет более 400 человек.

Российское представительство, как и вся компания, прошло через глобальную трансформацию. Начиная с 2007 года Merck приобрел и ввел в свою структуру несколько известных технологических компаний, которые имели российские представительства. В частности речь идет о швейцарском производителе биотехнологических лекарственных средств Serono, который стал частью биофармацевтического бизнеса, а компании Millipore и Sigma Aldrich влились в направление нашего лайф сайнс бизнеса. Слияния сделали Merck еще более значимым игроком как на глобальном уровне, так и в России, а структурные изменения помогли создать хорошо сбалансированный бизнес.

Ключевым вектором нашей стратегии в России стал трансфер технологий в партнерстве с ведущими российскими компаниями. Как я сказал ранее, в России локализованы контрактные производства наших лекарственных средств, а портфолио продуктов, предлагаемых подразделением лайф сайнс для создания современных научно-технологических решений, составляет более 300000 наименований, которые представлены шестью признанными мировыми брендами: Millipore, Milli-Q, Sigma-Aldrich, SAFC и BioReliance. Мы поддерживаем фармацевтические компании, разрабатывая биотехнологические процессы и оборудование, передаем технологии и делимся опытом, активно сотрудничаем с развивающимися отраслями, такими какпроизводство продуктов

Merck: новый бренд - новая стратегия. АНАЛИТИКА. 2015. № 6 . C. 6-12. питания и напитков. Поставляем оборудование и реагенты для работы научно-исследовательских групп, лабораторий контроля качества, контрольно-аналитических аккредитованных лабораторий и организаций, занимающихся мониторингом окружающей среды.

Какие программы Merck последних трех лет вы бы особенно отметили?

В России основной акцент делается на программы сотрудничества и партнерские взаимодействия с организациями

\section{Если вы хотите стать} первыми в своей области, в одиночку добиться желаемого невозможно, необходимо comрудничать

и научными институтами. Например, в конце 2018 года мы предложили проводить день предиабета в России. Это стало возможным благодаря нашему взаимодействию с эндокринологическим научным центром, которое закреплено в двухстороннем соглашении. Программа активно развивается, так как по разным данным в России каждый пятый находится в состоянии предиабета. Цель программы информировать людей о признаках, стадиях, причинах и опасности предиабета, который может перейти в тяжелое хроническое заболевание - сахарный диабет 2-го типа. Это лишь один из примеров. Есть и другие просветительские проекты, например, в области неврологии или репродуктивного здоровья. Более того, мы работаем над различными программами на Евразийском пространстве, способствуем обмену опытом.

Какой тип продукции фармацевтического подразделения Merck может стать востребованным на Российском рынке в ближайшее время?

Отмечу новейшую разработку - лекарственное средство для лечения рассеянного склероза в виде таблеток. Мы уже вывели этот продукт на мировой рынок и сейчас он проходит регистрацию в России. Препарат предназначен для пациентов с активной формой рассеянного склероза. Новое средство достаточно принимать короткими курсами по 10 дней в первый и второй год с начала лечения болезни. При этом терапия сохраняет свою клиническую эффективность в последующие два года без приема препарата. 
В области высокотехнологичных материалов я отметил бы новые пигменты. В России они востребованы в автомобильной промышленности и используются для создания лакокрасочных покрытий. В этой же сфере бизнеса мы предлагаем специальные красители для банкнот и идентификационных карточек.

Еще один продукт - безопасный и эффективный репеллент IR3535. К настоящему моменту только наша компания имеет разрешение на применение этой группы химических веществ для детей от трех месяцев и беременных женщин.

\section{Слияния сделали Merck еще более значимым}

\section{игроком как на}

\section{глобальном уровне,}

\section{так и в России}

Как вы оцениваете позиции компании Merck в России? Какова доля компании на нашем рынке?

Данные глобальной финансовой отчетности известны, а внутренняя политика компании не предполагает раскрытия сведений о результатах продаж в отдельных странах и регионах. Поэтому не назову конкретных чисел по

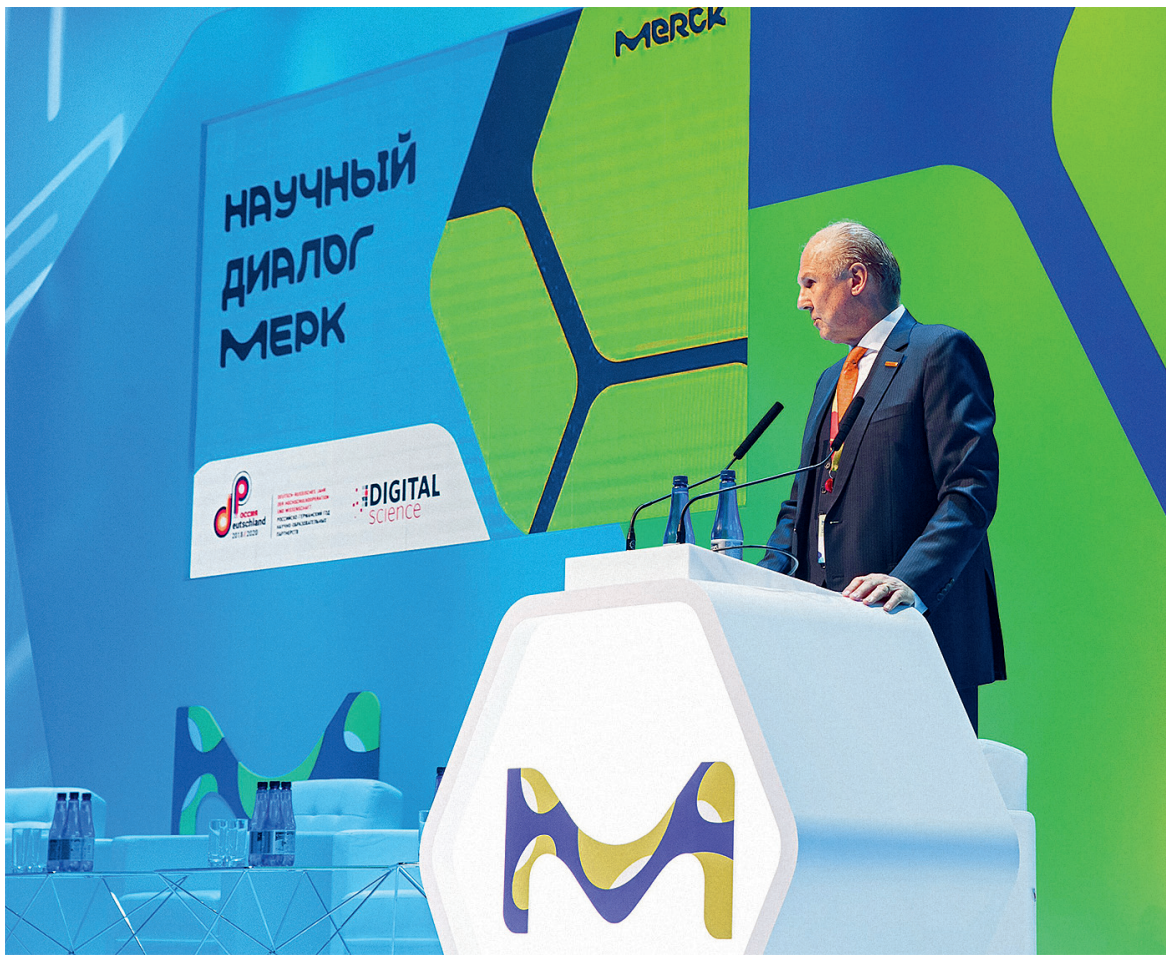

Юрген Кёниг открывает «Научный диалог Merck»
России, однако с уверенностью могу сказать, что российский рынок представляет для Merck стратегический интерес. По разным данным Евразия, включая Россию, - это 280 миллионов потенциальных потребителей. Демографическая ситуация в мире такова, что через 20 лет в Европе и Америке ожидается стагнация, а в странах Азии, Африки и СНГ численность населения будет расти. Мы связываем с этим планы по экономическому развитию и заинтересованы в расширении присутствия в перспективных регионах.

\section{Как меняется спрос на продукты Merck?}

В разных регионах и странах есть свои предпочтения, мы исследуем локальные запросы потребителей и предлагаем конкретные решения. Например, в России покупатели предпочитают иные цвета, чем в США - мы соответствующим образом изменяем цветовую гамму упаковки и промышленных красителей. В области лайф сайнс растет интерес к развитию фармацевтики, и мы предлагаем соответствующие новые технологии. Введение санкций стимулировало спрос на продукцию Merck в области производства продуктов питания и напитков. Российские производители повысили выработку и заинтересованы в повышении качества. Merck активно способствует этому. Могу сказать, что многие российские продукты и напитки сегодня неотличимы от европейских.

Скажите, пожалуйста, как вы собираете статистику по предпочтениям потребителей? У вас есть подразделение со специалистами в области психологии и социологии, или вы сотрудничаете с исследующими рынок компаниями?

У нас есть свои эксперты в штате, но если возникают специфичные вопросы, мы привлекаем внешних специалистов. Нам важно предлагать потребителю наилучшие возможные варианты и отслеживать тенденции в различных областях.

Есть ли в ваших планах открытие производства полного цикла нового лекарства для лечения рассеянного склероза в России подобно тому, как налажен выпуск сахароснижающего препарата?

В данный момент я не могу раскрывать планы компании. Однако хочу отметить, что мы провели тщательное исследование рынка, инспектировали производства, проверяли системы контроля всех технологических процессов - и нашли 


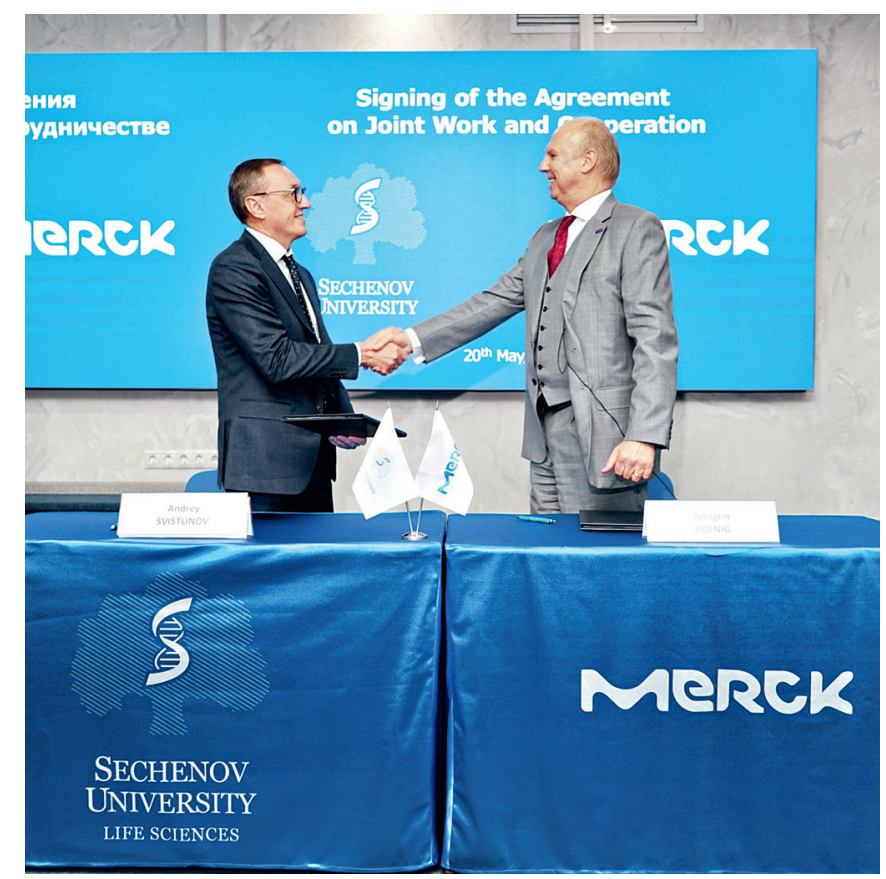

Соглашение о сотрудничестве подписали первый проректор Сеченовского университета Андрей Свистунов и Юрген Кёниг

российских партнеров, которые могут строго выдерживать предписанную технологию. Сейчас мы сотрудничаем с компаниями "Фармстандарт" и "Нанолек». Предваряю ваш следующий вопрос: почему мы не построили собственную фабрику? Ответ прост: в России уже имеется достаточно производственных мощностей. Некоторые зарубежные компании строят собственные заводы в России, но их реальная эффективность меньше проектных мощностей. Кроме того, строительство собственного производства Merck повысило бы себестоимость наших лекарственных средств.

Вы планируете реализовывать продукцию, которую производите в России, только у нас или экспортировать ее в другие страны?

Мы оцениваем возможности в данном направлении.

Расскажите, пожалуйста, о научных разработках Merck. У вас есть собственное научно-исследовательское подразделение или вы работаете на контрактной основе с научными институтами?

Merck имеет собственные научно-исследовательские подразделения в Дармштадте, Бостоне и Китае, крупные исследовательские центры высокотехнологических материалов находятся в Европе и Азии. Иногда мы локализуем исследования. В России мы также проводим клинические исследования, которые являются неотъемлемой частью разработок в области фармацевтики.
С какими российскими институтами и университетами вы сотрудничаете?

Мы работаем с разными научно-исследовательскими центрами в Москве, Санкт-Петербурге, Новосибирске и Владивостоке.

С какими организациями вы предпочитаете сотрудничать: государственными или частными?

Мы успешно сотрудничаем и с государственными, и с частными организациями. У нас нет особых предпочтений, главное для нас - качество и результат совместной работы.

\section{Расскажите о планах развития Merck.}

Мы стремимся развивать бизнес и раскрывать потенциал наших сотрудников, поскольку результаты компании зависят от команды. Наша цель - долгосрочное сотрудничество и профессиональное развитие наших специалистов. Merck предлагает прекрасные карьерные перспективы: за несколько лет многие российские сотрудники были переведены на долгосрочную и краткосрочную работу в США, Европу и Азию. Обмен опытом не только помогает профессионально развиваться, дает новые знания и понимание менталитета другой страны, но и обогащает нашу компанию. Инновационное мышление и любопытство - основные качества людей, которые предлагают новые подходы и решения.

\section{Структурные изменения помогли создать хорошо сбалансированный бизнес}

В каких российских регионах есть ваши представительства?

Головной офис и центральные склады Merck paсполагаются в Москве. Более 200 наших сотрудников распределены по всей стране, можно сказать, что мы присутствуем во всех часовых поясах России. В московском офисе работают коллеги из Германии, Австрии, Аргентины, Испании, Латвии.

Вы могли бы отметить какие-то конкретные будущие бизнес-проекты?

Не буду раскрывать детали, но вы вскоре о них услышите.

Спасибо за интересный рассказ!

СЮ. Кёнигом беседовапи

В. В. Родченкова и О. А. Лаврентьева 